\title{
A relationship between musculoskeletal pain and prognosis in hospitalized COVID-19 patients
}

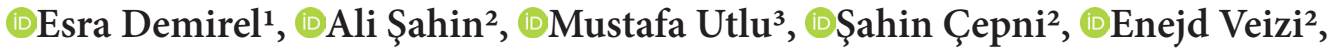 \\ (D) Betül Gülsüm Yavuz Veizi ${ }^{4}$ \\ ${ }^{1}$ Erzurum Regional Training and Research Hospital, Department of Orthopedics and Traumatology, Erzurum, Turkey \\ ${ }^{2}$ Ankara City Hospital, Department of Orthopedics and Traumatology, Ankara, Turkey \\ ${ }^{3}$ Erzurum Regional Training and Research Hospital, Department of Internal Medicine, Erzurum, Turkey \\ ${ }^{4}$ University of Health Sciences, Gülhane Training and Research Hospital, Faculty of Medicine, Division of Geriatrics, Ankara, Turkey
}

Cite this article as: Demirel E, Şahin A, Utlu M, Çepni Ş, Veizi E, Yavuz Veizi BG. A relationship between musculoskeletal pain and prognosis in hospitalized COVID-19 patients. J Health Sci Med 2021; 4(3): 300-305.

\begin{abstract}
Introduction: Musculoskeletal system complaints are often encountered in patients with COVID-19. The aim of this study was to evaluate the frequency of symptoms such as arthralgia, myalgia, and arthritis in hospitalized patients and their relationship with the final prognosis.

Material and Method: Complaints related to myalgia, arthralgia, arthritis-like symptoms, laboratory parameters, VAS scores and localized painful areas of 154 hospitalized patients who were treated with a COVID-19 diagnosis were recorded on admission and during their hospitalization period. The relationship between these clinical and laboratory data and the duration of hospital stays, need for intensive care and death-recovery states was evaluated.

Results: Of 154 cases, $45.5 \%(n=70)$ were female, $71.4 \%(n=110)$ had myalgia while $55.8 \%(n=86)$ had arthralgia. Mean VAS value was $6.39 \pm 2.04$. The most commonly reported painful locations were dorsum in $68.2 \%(n=75)$ and chest in $63.6 \%(n=70)$ of the patients. The death rate was significantly higher in patients with dorsum pain. $25-0 \mathrm{H}-\mathrm{Vitamin} \mathrm{D}$ levels did not have a significant effect on the prognosis and in terms of needing intensive care.

Conclusion: Myalgia and arthralgia are present in a significant part of patients with a diagnosis of COVID-19. Pain localized in the chest and dorsum area is associated with bad prognosis.
\end{abstract}

Keywords: COVID-19, myalgia, arthralgia, pain area, prognosis

\section{INTRODUCTION}

Since November 2019, the world has been struggling against the Severe Acute Respiratory Syndrome Coronavirus (SARS-CoV-2), which was firstly detected in Wuhan, China. Shortly after the outbreak, the World Health Organization (WHO) announced a pandemic, and the disease has now become a global health problem (1).

Symptoms are often non-specific, and the condition appears with changing severity from asymptomatic infection to severe and sometimes fatal respiratory tract infections (2-5). Another feature of COVID-19 is its mild onset which tends to progress to severe stages. The increase in hospitalization rates has brought healthcare systems close to breaking point in many countries. It is extremely important to have early diagnosis and treatment plans in order to shorten the duration of hospital stay (4).
The most common symptoms experienced by COVID-19 patients are fever, dry cough, dyspnea, muscle-joint pains, headache, smell-taste disorders, diarrhea followed by less common conjunctivitis and dermatitis (6). Though its spike protein, the virus attaches to the transmembrane protease serine 2 (TMPRSS2) and angiotensin-converting enzyme 2 (ACE2) receptors in the human organism. Pathological changes in the musculoskeletal system occur with the exposure of the muscle, synovium and bone cells containing these receptors to the viral infection or due to the effects of cytokines and proinflammatory agents $(1,4)$.

Musculoskeletal symptoms such as fatigue, myalgia and arthralgia are common COVID-19 symptoms but the prevalence of these are yet to be examined systematically $(7,8)$. Additionally, chronic pains such as headache and 
neck, back, orofacial and cervical/lumbar pain tends to get worse with disease progression and these patients might need additional care and support as their need for analgesic will increase (9).

This study examines the prevalence of myalgia, arthralgia, and arthritis-like symptoms in hospitalized patients diagnosed with COVID-19 and the relationship between musculoskeletal pains and COVID-19 prognosis.

\section{MATERIAL AND METHOD}

The study was carried out with the permission of Erzurum Regional Training and Development Hospital Clinical Researches Ethics Committee (Date: 02.11.2020, Decision No: 2020/20-194)

\section{Patient Selection}

This prospective longitudinal study was performed at the Erzurum Regional Training and Development Hospital and included consecutive hospitalized patients diagnosed with COVID-19 between December 2020 and January 2021. Inclusion criteria were patients older than 18 , with a confirmed diagnosis of PCR (+) COVID-19 and who were treated as an inpatient case. Pregnant women, patients with active malignity, those with a history of inflammatory disease or fibromyalgia prior to admission, those with chronic liver and kidney disorders, patients with known vertebral and disc pathologies, and patients on antidepressant medicaments were excluded from the study. A total of 154 patients who met these criteria and volunteered to participate were included in the final analyses.

\section{Data Gathering}

The hospitalization indications for patients with a diagnosis of COVID-19 in the emergency service and outpatient clinic were pneumonia symptoms and with consistent $\mathrm{X}$-ray or tomography findings, patients with a $\mathrm{SpO}_{2}$ level lower than $90 \%$, patients with severe coughing associated with severe musculoskeletal pain, and patients who could not continue outpatient treatment. Vital signs, white blood cell (WBC), c-reactive protein (CRP), ferritin, D-dimer, and 25 hydroxy vitamin $\mathrm{D}$ (vit-D) values were recorded for all patients upon admission. A clinician made a detailed explanation to all patients during hospitalization and patients were asked to grade their pain from 1 to 10 according to the visual analog scale (VAS). Myalgia, arthralgia and arthritis-like complaints and symptoms were evaluated. The pain diagram (Figure), which was defined by Margolis $(10,11)$ and divides the body into 45 separate areas, was simplified into eight areas (neck, arm, chest, dorsum, back, thigh, leg and foot) and presented to patients who defined myalgia. They were asked to specify painful areas.
Transfer to the intensive care unit (ICU) was performed after consulting with the intensive care unit physician and it was reserved for patients who developed dyspnea and tachypnea, those with a respiratory rate of $\geq 30 / \mathrm{min}$ or $\mathrm{PaO}_{2} / \mathrm{FiO}_{2}<300$, those with an increased oxygen need during the follow-up whose $\mathrm{SpO}_{2}$ was $<90 \%$ or $\mathrm{PaO}_{2}$ was $<70 \mathrm{mmHg}$ (despite $5 \mathrm{~L} / \mathrm{min}$ oxygen treatment), those who developed hypotension (systolic blood pressure $<90 \mathrm{mmHg}$ and average artery pressure $<65 \mathrm{mmHg}$ ), patients with an acute organ dysfunction (such as acute kidney damage, acute liver dysfunction, confusion, acute hemorrhagic diathesis), patients who developed arrhythmia and had an increased troponin level and those with a lactate level of $>4 \mathrm{mmol}$. The total duration of hospital stays, the need for intensive care and deceased patients were recorded.

\section{Statistical Analyses}

Number Cruncher Statistical System (NCSS) program was used for statistical analyses. Descriptive statistical methods (mean, standard deviation, median, frequency, percentage, minimum, maximum) were used to evaluate the data. The conformity of quantitative data with the normal distribution was tested with the Shapiro-Wilk test and graphic examinations. The Student-t test was used for the binary intergroup comparisons of the quantitative variables with normal distribution while Mann-Whitney $\mathrm{U}$ test was used for the binary inter-group comparisons of the quantitative variables without normal distribution. The Pearson chi-square test, Fisher's exact test and FisherFreeman-Halton exact test were used for the comparison of qualitative data. The Spearman correlation test was used to evaluate the relationships between the qualitative data. The statistical significance was $\mathrm{p}<0.05$.

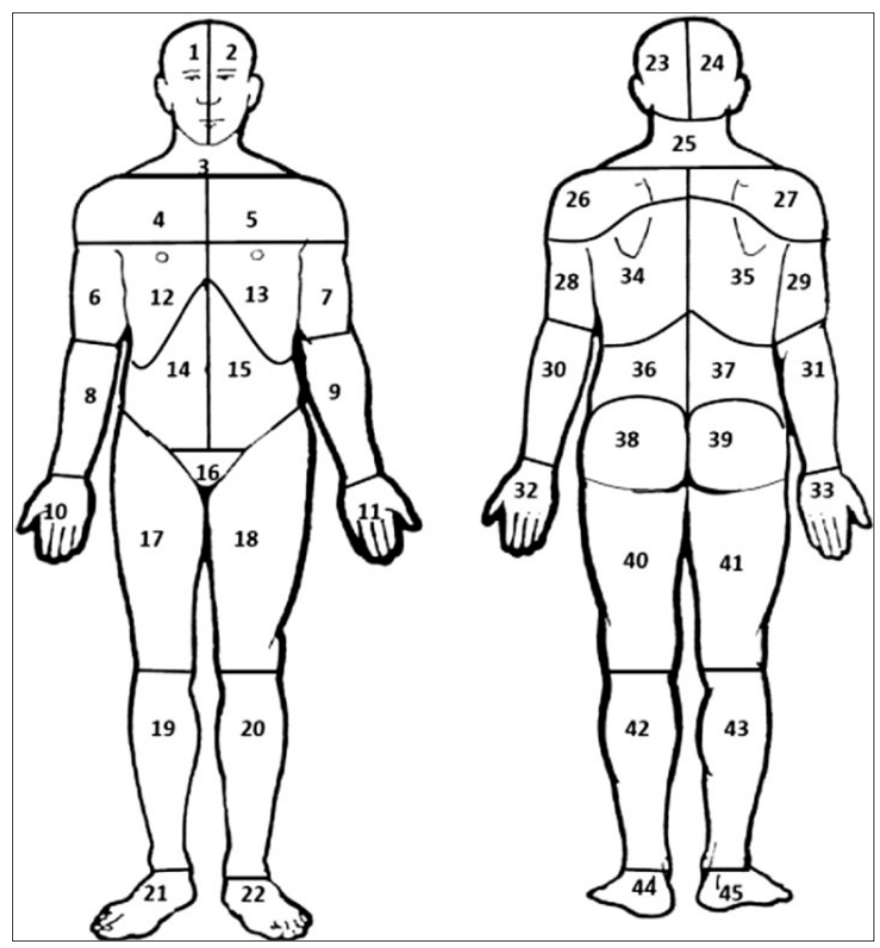

Figure. Template for identifying painful areas 


\section{RESULTS}

The study was conducted with 154 cases of whom $45.5 \%$ $(n=70)$ were female. Mean age was 63.66 (range 21-89) years. Of the cases included in the study, $71.4 \%(\mathrm{n}=110)$ had myalgia, 55.8\% $(n=86)$ had arthralgia. Mean VAS value on admission was $6.39 \pm 2.04$. The mean duration of hospital stay of patients was $12.83 \pm 7.08$ (4-35) days. Data on all demographic and descriptive variables are shown on Table 1.

The most common painful regions reported by the patients were dorsum $(68.2 \% ; n=75)$ and chest $(63.6 \%$; $\mathrm{n}=70$ ). A strong correlation was found between the need for intensive care and back and chest pain on admission $(\mathrm{p}=0.015$ and $\mathrm{p}=0.001$ respectively). There was no significant correlation between other localizations of pain and the need for intensive care (Table 2).

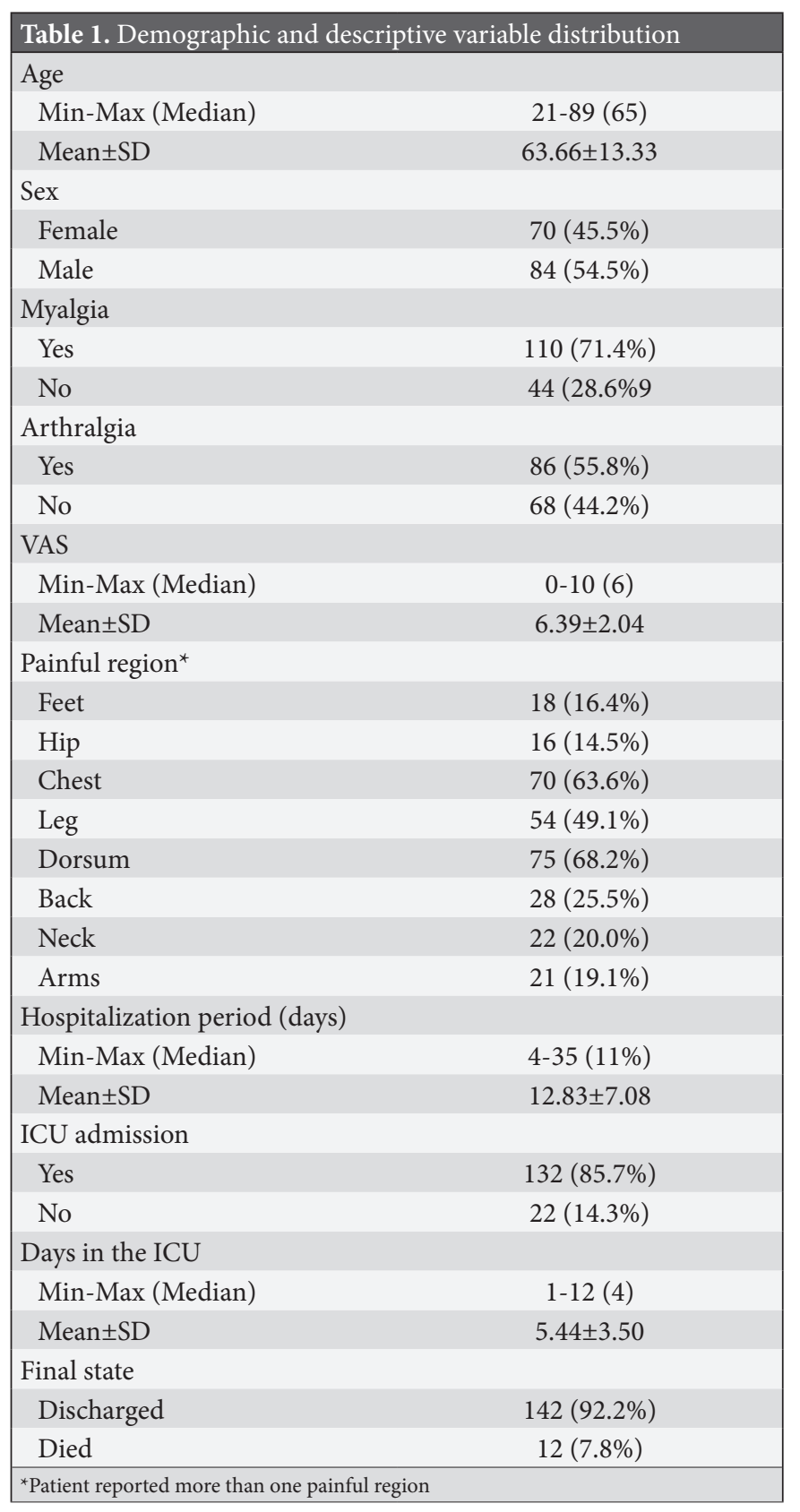

There was a significant positive correlation between high CRP, WBC, and D-dimer values and the need for intensive care $(p<0.05)$. No significant differences and correlations were found between the other parameters. All data is shown on Table 3.

\begin{tabular}{|c|c|c|c|}
\hline & \multicolumn{2}{|c|}{ Need for ICU } & \multirow{2}{*}{$P$ value } \\
\hline & No & Yes & \\
\hline VAS & & & ${ }^{\mathrm{a}} 0.280$ \\
\hline Min-Max (Median) & $0-10(6)$ & $4-10(6)$ & \\
\hline Mean \pm SD & $6.42 \pm 2.04$ & $6.18 \pm 2.08$ & \\
\hline \multicolumn{4}{|l|}{ Pain localization } \\
\hline Feet & & & ${ }^{\mathrm{b}} 0.076$ \\
\hline No & $108(83.1)$ & $22(16.9)$ & \\
\hline Yes & $18(100.0)$ & $0(0.0)$ & \\
\hline Hip & & & ${ }^{\mathrm{b}} 0.130$ \\
\hline No & $110(83.3)$ & $22(16.7)$ & \\
\hline Yes & $16(100.0)$ & $0(0.0)$ & \\
\hline Chest & & & ${ }^{c} 0.001$ \\
\hline No & $74(94.9)$ & $4(5.1)$ & \\
\hline Yes & $52(74.3)$ & $18(25.7)$ & \\
\hline Leg & & & ${ }^{c} 0.990$ \\
\hline No & $80(85.1)$ & $14(14.9)$ & \\
\hline Yes & $46(85.2)$ & $8(14.8)$ & \\
\hline Dorsum & & & ${ }^{c} 0.945$ \\
\hline No & $62(49.2)$ & $11(50.0)$ & \\
\hline Yes & $64(50.8)$ & $11(50.0)$ & \\
\hline Back & & & ${ }^{\mathrm{b}} 0.015$ \\
\hline No & $98(81.7)$ & $22(18.3)$ & \\
\hline Yes & $28(100.0)$ & $0(0.0)$ & \\
\hline Neck & & & ${ }^{\mathrm{b}} 0.745$ \\
\hline No & $108(85.7)$ & $18(14.3)$ & \\
\hline Yes & $18(81.8)$ & $4(18.2)$ & \\
\hline Arms & & & ${ }^{\mathrm{b}} 0.741$ \\
\hline No & $107(84.3)$ & $20(15.7)$ & \\
\hline Yes & $19(90.5)$ & $2(9.5)$ & \\
\hline
\end{tabular}

Table 3. Relationship between need for ICU and laboratory findings

\begin{tabular}{|lccc|}
\hline & \multicolumn{2}{c}{ Need for ICU } & $\begin{array}{c}\text { P } \\
\text { value }\end{array}$ \\
\cline { 2 - 3 } WBC & & Yes & ${ }^{\mathrm{d}} 0.010$ \\
Min-Max (Median) & $2.4-23.5(7.2)$ & $6.1-14.3(10.5)$ & \\
Mean \pm SD & $8.12 \pm 3.68$ & $10.25 \pm 2.57$ & \\
CRP & & & \\
Min-Max (Median) & $0.5-215(41)$ & $0.5-248(97)$ & \\
Mean \pm SD & $55.58 \pm 50.24$ & $108.25 \pm 80.95$ & \\
Ferritin & & & \\
Min-Max (Median) & $30-1650(330.5)$ & $97-917(351)$ & \\
Mean \pm SD & $473.94 \pm 457.5$ & $383.82 \pm 243.83$ & \\
25-OH-Vitamin D & & & \\
Min-Max (Median) & $4.4-67.5(12.9)$ & $9.2-25(17.5)$ & \\
Mean \pm SD & $16.26 \pm 10.79$ & $17.43 \pm 6.44$ & \\
D-Dimer & & & \\
Min-Max (Median) & $0.2-4261(715)$ & $190-4170(1230)$ & \\
Mean \pm SD & $987.26 \pm 961.45$ & $1668.73 \pm 1273.02$ & \\
\hline${ }^{a}$ Mann Whitney U test, ${ }^{\mathrm{d} S t u d e n t-t ~ t e s t ~}$ & \multicolumn{3}{c}{} \\
\hline
\end{tabular}


The fatality rate of cases with chest pain was significantly higher than those without $(\mathrm{p}<0.01)$. Similarly, the fatality rate of cases with dorsum pain was also significantly higher than those without $(\mathrm{p}<0.05)$ (Table 4).

High WBC and D-dimer values during the hospitalization were associated with high fatality risk. Vitamin D levels of deceased patients were significantly higher compared to those who recovered $(\mathrm{p}<0.05)$. There was no statistical correlation between ferritin and CRP values and death rate (Table 5).

A significant positive correlation was found between high VAS values on admission and the duration of hospital stay $(p<0.05)$. There also was a significant positive correlation between CRP, ferritin and D-dimer values of the cases and their duration of hospital stay $(p<0.05)$. Higher CRP, ferritin and D-dimer values on admission were correlated to a longer hospital stay. All relative data is presented on Table 6.

\section{Table 4. Relationship between end-result and pain localization}



Table 5. Relationship between end-result and laboratory findings

\begin{tabular}{|c|c|c|c|}
\hline & \multicolumn{2}{|c|}{ End-result } & \multirow{2}{*}{ p value } \\
\hline & Discharge $(n=142)$ & Death $(n=12)$ & \\
\hline WBC & & & ${ }^{\mathrm{a}} 0.020^{*}$ \\
\hline Min-Max (Median) & $2.4-23.5(7.5)$ & $6.1-14.3(11.5)$ & \\
\hline Mean \pm SD & $8.25 \pm 3.61$ & $10.53 \pm 3.08$ & \\
\hline CRP & & & ${ }^{\mathrm{a}} 0.157$ \\
\hline Min-Max (Median) & $0.5-248(43)$ & $1.3-152(94.5)$ & \\
\hline Mean \pm SD & $61.69 \pm 58.92$ & $79.88 \pm 49.91$ & \\
\hline Ferritin & & & ${ }^{\mathrm{a}} 0.112$ \\
\hline Min-Max (Median) & $30-1650(324)$ & $97-917(590)$ & \\
\hline Mean \pm SD & $453.01 \pm 442.47$ & $556.33 \pm 315.87$ & \\
\hline 25-OH-Vitamin D & & & ${ }^{\mathrm{a}} 0.04$ \\
\hline Min-Max (Median) & $4.4-67.5(12.9)$ & $10.7-25(22)$ & \\
\hline Mean \pm SD & $16.17 \pm 10.53$ & $19.38 \pm 6.11$ & \\
\hline D-Dimer & & & ${ }^{\mathrm{a}} 0.003$ \\
\hline Min-Max (Median) & $0.2-4261(697.5)$ & $630-3288(1889)$ & \\
\hline Mean \pm SD & $1015.76 \pm 1013.22$ & $1913.67 \pm 990.67$ & \\
\hline
\end{tabular}

\section{Table 6. Effect of variables on hospitalization time}

\begin{tabular}{|lcc|} 
& \multicolumn{2}{c|}{ Hospitalization time } \\
\cline { 2 - 3 } & $\mathbf{r}$ & $\mathbf{p}$ \\
\hline VAS & 0.205 & 0.011 \\
WBC & -0.040 & 0.624 \\
CRP & 0.177 & 0.028 \\
Ferritin & 0.161 & 0.046 \\
25-OH Vitamin D & 0.109 & 0.227 \\
D-dimer & 0.231 & 0.005 \\
\hline r=Spearman's correlation coefficient & & \\
\hline
\end{tabular}

\section{DISCUSSION}

The results of our study clearly show a high incidence of musculoskeletal pain in COVID patients with chest and dorsum being the most prominent ones. Pain in these regions was strongly correlated with need for ICU and fatality rate. A high VAS score on admission was also an indicator of longer hospital stay.

Myalgia, arthralgia, fatigue and rarely arthritislike symptoms can be seen in individuals infected with COVID-19 (12). Although musculoskeletal system symptoms in general were evaluated in many studies $(4,5,12,13)$, the systematic prevalence studies primarily focused on this subject are not yet sufficient. Musculoskeletal symptoms are most probably evaluated behind severe clinical tables such as severe respiratory symptoms, cardiovascular involvements and multiple organ failures. The role of the musculoskeletal system has not been examined in detail during this pandemic (14). Generally, indirect effects due to inflammatory and/or immune response are regarded as the cause of arthralgia and myalgia (4). This study found that myalgia (71.4\%) and arthralgia (55.8\%) are common symptoms in hospitalized COVID-19 patients. This is in accordance with what other 
previous studies have shown in this regard (13-16). In addition to the emergence of new painful regions due to the disease itself, chronic painful conditions may also worsen and symptoms like myalgia and arthralgia might affect the patient's ability to perform their daily life activities $(17,18)$. Pain management should be considered an important part of the treatment algorithm.

The most common risk factors for mortality in the prognosis of the COVID-19 are multilobular infiltration in the lungs, lymphopenia, the existence of bacterial coinfection, the history of smoking, hypertension and age parameters $(19,20)$. The existence of myalgia in the early period of the disease with high ALT and high hemoglobin levels was shown as a predictive indicator of severe SARS-CoV-2 infection (21). There are studies which assert that myalgia is not associated with the severity and death rate of the disease $(22,23)$. In this study we found the most common painful regions related to myalgia to be the dorsum area $(68.2 \% ; n=75)$ and chest (63.6\%; $n=70)$. The results of this study comply with the study by Uz et al. (24) where the symptom of back pain was the second most common symptom after fatigue with a ratio of $50.5 \%$.

This study also tried to determine the effect of myalgic localizations on the prognosis and final end-result. Pain localized in the chest and dorsum areas was associated with bad prognosis. This was not a surprising result. Hyperfunction of intercostal muscles to compensate for oxygen deficiency due to pneumonia may explain pain in these areas $(14,22)$. Moreover, pneumonia with peripheral involvement may spread to the parental pleura and stimulate the intercostal nerves resulting in pleuritic chest pain and back pain through related dermatomes (25). Back pain was also associated with relatively good prognosis. However, this might be due to the fact that patient back pain was overshadowed by their painful dorsum.

Vitamin D is responsible for the maintenance of a healthy skeleton through regulation of calcium and phosphate metabolism. It is also an immunomodulatory hormone. Experimental studies have shown that the active form of vit-D, exerts immunologic activities on the innate and adaptive immune system. Many immune-related diseases and conditions such as psoriasis, type 1 diabetes, multiple sclerosis, rheumatoid arthritis, tuberculosis, sepsis, respiratory infection, and COVID-19 have been associated with low levels of serum 25-hydroxyvitamin $\mathrm{D}$ (26). While vit-D deficiency has been associated with reduced ambulation after hip fracture surgery (27) and it also pre-disposes patients to decreased odds of remission to inflammation (28). The effect of vit-D on hospitalization and fatality rate in SARS-CoV-2 infection has often been discussed in the literature. Many studies assert that vit-D deficiency has a negative effect on the prognosis of pneumonia due to COVID-19 or other reasons (29-31). However, this hypothesis contradicts the high case and death rates in equatorial countries that are advantageous in terms of benefiting from the sunlight such as Brazil. Some studies assert that low vit-D values does not have any effect on pneumonia prognosis or is associated with low mortality $(32,33)$. This study found no risk in terms of ICU admission rates with regard to vit-D values. The vit-D values of deceased patients were slightly higher than those who recovered but this could have been influenced by our small number of patients. Although the effects of vit-D on the musculoskeletal system are known, its effect on the immune system needs further research. A drawback on this subject is that COVID-19 patients may experience secondary vit-D deficiency as a result of them remaining still for a long time and being devoid of sunlight due to isolation. Therefore, the researchers are of the opinion that patients may face increased risk of fracture in the following period. Further research is required on this topic.

This study has some limitations. Firstly, the study included only adults of 18 years of age and higher. There might be differences in the expression of pain in lower age populations and so our results are only valid for the adult age groups. The second limitation is that the small sample size of patients who needed intensive care $(\mathrm{n}=22)$ and deceased patients $(n=12)$. Because of this, the study might be insufficient in showing the relationship between musculoskeletal system pains and laboratory findings in the COVID-19 patients. More studies will be needed to reveal the uncertainties on this subject.

\section{CONCLUSION}

The majority of hospitalized patients in this study who were diagnosed with COVID-19, had musculoskeletal system pain. The study revealed that the probability of patients with chest and dorsum pain to have a worse prognosis is relatively high. This information might help clinicians in predicting the prognosis during treatment. Additionally, even though the pains in other areas are not specifically associated with the prognosis, they are among the problems that must be solved at the treatment stage.

\section{ETHICAL DECLARATIONS}

Ethics Committee Approval: The study was carried out with the permission of Erzurum Regional Training and Development Hospital Clinical Researches Ethics Committee (Date: 02.11.2020, Decision No: 2020/20194).

Informed Consent: All patients signed the free and informed consent form.

Referee Evaluation Process: Externally peer-reviewed. 
Conflict of Interest Statement: The authors have no conflicts of interest to declare.

Financial Disclosure: The authors declared that this study had received no financial support.

Author Contributions: All of the authors declare that they have all participated in the design, execution, and analysis of the paper and approved the final version.

\section{REFERENCES}

1. Fraser DD, Cepinskas G, Slessarev M, et al. Inflammation Profiling of Critically Ill Coronavirus Disease 2019 Patients. Crit Care Explor 2020; 2: e0144.

2. Kotfis K, Skonieczna-Zydecka K. COVID-19: gastrointestinal symptoms and potential sources of SARS-CoV-2 transmission. Anaesthesiol Intensive Ther 2020; 52: 171-2.

3. Gu J, Han B, Wang J. COVID-19: Gastrointestinal manifestations and potential fecal-oral transmission. Gastroenterology 2020; 158: 1518-9.

4. Huang C, Wang Y, Li X, et al. Clinical features of patients infected with 2019 novel coronavirus in Wuhan, China. Lancet 2020; 395: 497-506.

5. Park SE. Epidemiology, virology, and clinical features of severe acute respiratory syndrome -coronavirus-2 (SARS-CoV-2; Coronavirus Disease-19). Clin Exp Pediatr 2020; 63: 119-24.

6. Zhou F, Yu T, Du R, et al. Clinical course and risk factors for mortality of adult inpatients with COVID-19 in Wuhan, China: a retrospective cohort study. Lancet 2020; 395: 1054-62.

7. Pung R, Chiew CJ, Young BE, et al. Investigation of three clusters of COVID-19 in Singapore: implications for surveillance and response measures. Lancet 2020; 395: 1039-46.

8. Godaert L, Proye E, Demoustier-Tampere D, Coulibaly PS, Hequet F, Drame M. Clinical characteristics of older patients: The experience of a geriatric short-stay unit dedicated to patients with COVID-19 in France. J Infect 2020; 81: e93-e4.

9. Drozdzal S, Rosik J, Lechowicz K, et al. COVID-19: pain management in patients with SARS-CoV-2 infection-molecular mechanisms, challenges, and perspectives. Brain Sci 2020; 10: 465.

10. Kotfis K, Zegan-Barańska M, Szydłowski Ł, Żukowski M, Ely EW. Methods of pain assessment in adult intensive care unit patientsPolish version of the CPOT (Critical Care Pain Observation Tool) and BPS (Behavioral Pain Scale). Anaesthesiol Intensive Ther 2017; 49: 66-72.

11. Margolis RB, Tait RC, Krause SJ. A rating system for use with patient pain drawings. Pain 1986; 24: 57-65.

12. Park M, Cook AR, Lim JT, Sun Y, Dickens BL. A Systematic review of COVID-19 epidemiology based on current evidence. J Clin Med 2020; 9: 967.

13. Chen N, Zhou M, Dong X, et al. Epidemiological and clinical characteristics of 99 cases of 2019 novel coronavirus pneumonia in Wuhan, China: a descriptive study. Lancet 2020; 395: 507-13.

14. Cipollaro L, Giordano L, Padulo J, Oliva F, Maffulli N. Musculoskeletal symptoms in SARS-CoV-2 (COVID-19) patients. Springer; 2020.

15.Lechien JR, Chiesa-Estomba CM, De Siati DR, et al. Olfactory and gustatory dysfunctions as a clinical presentation of mildto-moderate forms of the coronavirus disease (COVID-19): a multicenter European study. Eur Arch Otorhinolaryngol 2020; 277: 2251-61.

16. Ebrahim SH, Memish ZA. COVID-19 -the role of mass gatherings. Travel Med Infect Dis 2020; 34: 101617.

17. Hartman-Maeir A, Soroker N, Ring H, Avni N, Katz N. Activities, participation and satisfaction one-year post stroke. Disabil Rehabil 2007; 29: 559-66.
18. Huang YH, Wu CY, Hsieh YW, Lin KC. Predictors of change in quality of life after distributed constraint-induced therapy in patients with chronic stroke. Neurorehabil Neural Repair 2010; 24: 559-66.

19. He J, Song C, Liu E, et al. Establishment of routine clinical indicators-based nomograms for predicting the mortality in patients with COVID-19. 2020. Doi:10.21203/rs.3.rs-125447/v1

20. Shi Y, Yu X, Zhao H, Wang H, Zhao R, Sheng J. Host susceptibility to severe COVID-19 and establishment of a host risk score: findings of 487 cases outside Wuhan. Crit Care 2020; 24: 108.

21.Jiang X, Coffee M, Bari A, et al. Towards an artificial intelligence framework for data-driven prediction of coronavirus clinical severity. Computers, Materials \& Continua 2020; 63: 537-51.

22.Lippi G, Wong J, Henry BM. Myalgia may not be associated with severity of coronavirus disease 2019 (COVID-19). World J Emerg Med 2020; 11: 193-4.

23. Chen T, Wu D, Chen H, Yan W, Yang D, Chen G. Clinical characteristics of 113 deceased patients with coronavirus disease 2019: retrospective study. BMJ 2020; 368: m1295.

24. Uz C, Umay E, Gundogdu I, Uz F. Back pain and related factors in patients with COVID-19. 2020.

25.Lee RW, Hodgson LE, Jackson MB, Adams N. Problem based review: pleuritic chest pain. Acute Med 2012; 11: 172-82.

26. Charoenngam N, Holick MF. Immunologic effects of vitamin D on human health and disease. Nutrients 2020; 12: 2097.

27. Hao L, Carson JL, Schlussel Y, Noveck H, Shapses SA. Vitamin D deficiency is associated with reduced mobility after hip fracture surgery: a prospective study. Am J Clin Nutr. 2020; 112: 613-618.

28. Winter RW, Collins E, Cao B, Carrellas M, Crowell AM, Korzenik JR. Higher 25-hydroxyvitamin D levels are associated with greater odds of remission with anti-tumour necrosis factor- $\alpha$ medications among patients with inflammatory bowel diseases. Aliment Pharmacol Ther 2017; 45: 653-659.

29. Daneshkhah A, Agrawal V, Eshein A, Subramanian H, Roy HK, Backman V. The possible role of vitamin D in suppressing cytokine storm and associated mortality in COVID-19 patients. MedRxiv 2020.

30. Dancer RC, Parekh D, Lax S, et al. Vitamin D deficiency contributes directly to the acute respiratory distress syndrome (ARDS). Thorax 2015; 70: 617-24.

31. Jones SE, Maddocks M, Kon SS, et al. Sarcopenia in COPD: prevalence, clinical correlates and response to pulmonary rehabilitation. Thorax 2015; 70: 213-8.

32. Amrein K, Zajic P, Schnedl C, et al. Vitamin D status and its association with season, hospital and sepsis mortality in critical illness. Crit Care 2014; 18: R47.

33. Amrein K, Schnedl C, Holl A, et al. Effect of high-dose vitamin D3 on hospital length of stay in critically ill patients with vitamin D deficiency: the VITdAL-ICU randomized clinical trial. JAMA 2014; 312: 1520-30. 